\title{
TRATAMIENTO ENDOSCÓPICO DEL REFLUJO VESICOURETERAL: HALLAZGOS HISTOLÓGICOS
}

\author{
María López Díaz, Francisco López Vázquez, Andrés Gómez Fraile, Adolfo Aransay Bramtot, Daniel \\ Cabezali Barbancho y Raquel Tejedor Sánchez.
}

Servicio de Cirugía Pediátrica. Hospital Universitario 12 de Octubre. Madrid. España.

Resumen.- OBJETIVO: El reflujo vesicoureteral es una patología con diferentes formas de manejo terapéutico, una de las cuales es la inyección vía endoscópica de diferentes materiales. Mostramos algunos cambios histológicos que producen estos materiales en la pared vesical.

MÉTODOS: Estudiamos 3 muestras de uréter intravesical en 3 niños afectos de reflujo vesicoureteral. Las muestras se obtuvieron durante la reimplantación de los uréteres, extirpando la porción más distal de los uréteres.

RESULTADOS: Mostramos los cambios encontrados con los diferentes materiales estudiados (politetrafluoroetileno, polidimetilsiloxano, copolímero de dextranómero y ácido hialurónico) observando una menor formación de tejido conjuntivo con los 2 últimos.
María López Díaz

Paseo de la Reina Cristina, 24 - 6 2

28014. Madrid. (España).

maria_lopez_d@yahoo.es
CONCLUSIONES: Se describen migraciones y granulomas con diferentes materiales y se constata la reacción de cuerpo extraño y fibrosis en la pared vesical. Son necesarios más estudios en humanos para determinar el mejor producto de inyección endoscópica.

Palabras clave: Reflujo vesicoureteral. Tratamiento endoscópico. Politetrafluoroetileno. Polidimetilsiloxano. Copolímero de dextranómero y ácido hialurónico. Histología.

Summary.- OBJECTIVES: Vesicoureteral reflux is a pathologic entity with different forms of therapeutic management, one of which is endoscopic injection of various materials. We show some histological changes produced by these materials in the bladder wall.

METHODS: We study three samples of intravesical ureter from three children suffering vesicoureteral reflux. The ureters were obtained during ureteral reimplantation surgery.

RESULTS: We show the changes found with various materials under study (polytetrafluorethylene, polydimethylsiloxane, hyaluronic acid and dextranomer copolimer) observing less conjunctive tissue with the two latter and with the more encapsulated hyaluronic acid - dextranomer copolimer.

CONCLUSIONS: Migrations and granulomas are described with various materials and we ascertained the presence of foreign body reaction and fibrosis within the bladder wall. More studies in human beings are required to determine the best product for endoscopic injection.

Keywords: Vesicoureteral reflux. Endoscopic treatment. Polytetrafluorethylene. Polydimethylsiloxane. Hyaluronic acid and dextranomer copolimer. Histology. 


\section{INTRODUCCIÓN}

El reflujo vesicoureteral (RVU) es una patología frecuente en la infancia (aproximadamente un 1\%-2\% de la población) (1). Existen varias opciones en el tratamiento de esta enfermedad sin consenso en el uso de las mismas (2, 3).

El RVU es una patología que a largo plazo puede tener graves consecuencias. Los niños con RVU no tienen mayor riesgo de infección del tracto urinario (ITU) (4), sin embargo, sí tienen mayor riesgo de pielonefritis y cicatrices renales tras ITU. Estas cicatrices renales y pielonefritis en el adulto pueden finalizar en hipertensión y fallo renal $(5,6)$.

Las opciones de manejo del RVU incluyen el tratamiento expectante, la profilaxis antibiótica, el tratamiento endoscópico y la cirugía (abierta o laparoscópica). Dentro del tratamiento endoscópico se han usado varios tipos de materiales de inyección desde los años 80: politetrafluoroetileno (Teflon $®$ ), polidimetilsiloxano (Macroplástico $®$ ), hidroxiapatita cálcica, colágeno, copolímero de dextranómero y ácido hialurónico (Deflux®), poly(acrylonitrile)-based hydrogel (Hypan®), etc $(7,8)$.

Estos materiales de inyección tienen diferentes características en cuanto a su composición, esto hace que su comportamiento en la inyección intravesical sea diferente y por tanto su espectro histológico en la pared del uréter intravesical. De carácter biológico tenemos el copolímero de dextranómero y ácido hialurónico que está formado por microesferas de dextrano (80-250 $\mu \mathrm{m})$ en una solución al $50 \%$ de hialuronidasa sódica. Las microesferas de dextranómero empiezan a reabsorberse en 3-4 meses, siendo reemplazadas por un volumen 20-25\% menor de secreción endógena de colágeno, provocando a largo plazo una disminución del volumen submucoso del habón implantado.

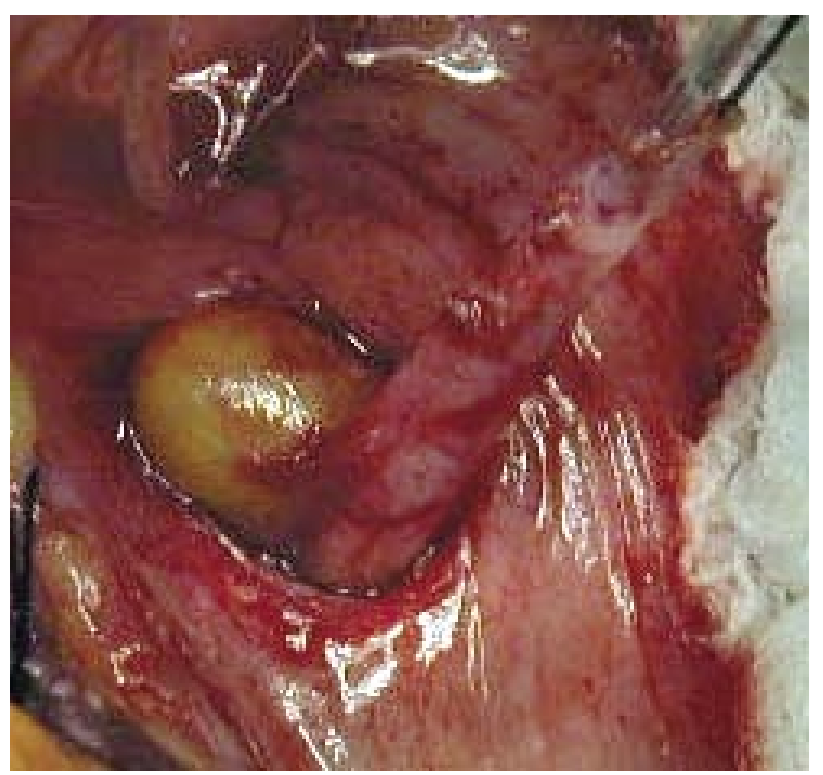

FIGURA 1. Fuerte adherencia del material inyectado a los tejidos adyacentes con una intensa reacción a cuerpo extraño.
La hialuronidasa sódica se reabsorbe en 1-2 semanas, provocando asimismo una disminución del habón inyectado a partir de la $3^{\mathrm{a}}$ semana. Dentro de los sintéticos están el Teflon ${ }^{2}$ que son micropartículas de politetrafluoroetileno en

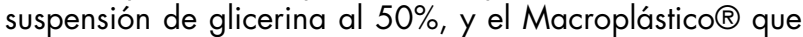
está formado por un $40 \%$ de micropartículas de silicona (polidimetilsiloxano), en suspensión de hidrogel reabsorbible $60 \%$; el hidrogel, es sustituido por un volumen de colágeno endógeno, similar al volumen inyectado. El tamaño de las partículas varía en estos rangos Teflon®: 4-100 um; Macroplástico®: 10-400 $\mu \mathrm{m}$; Deflux®: 80-250 $\mu \mathrm{m}$.

Dada la amplia gama de materiales inyectables se hace difícil la elección del "mejor" producto de inyección. Todavía no existe un inyectable ideal, aunque se busca un material entre otras cosas, persistente, no antigénico, barato, sin efectos secundarios, que no forme granuloma, y que no tenga la capacidad de migrar a otros tejidos, etc (7). Pero entre todas las características de este material ideal, también se debe incluir el tipo de reacción que produce en la vejiga de estos niños. Un determinado tipo de materiales hace mayor reacción a cuerpo extraño, otros mayor fibrosis. También es importante ver que materiales se reabsorben y sustituyen por colágeno, cuales no, cuales pierden volumen y cuánto, etc. Presentamos un ejemplo de

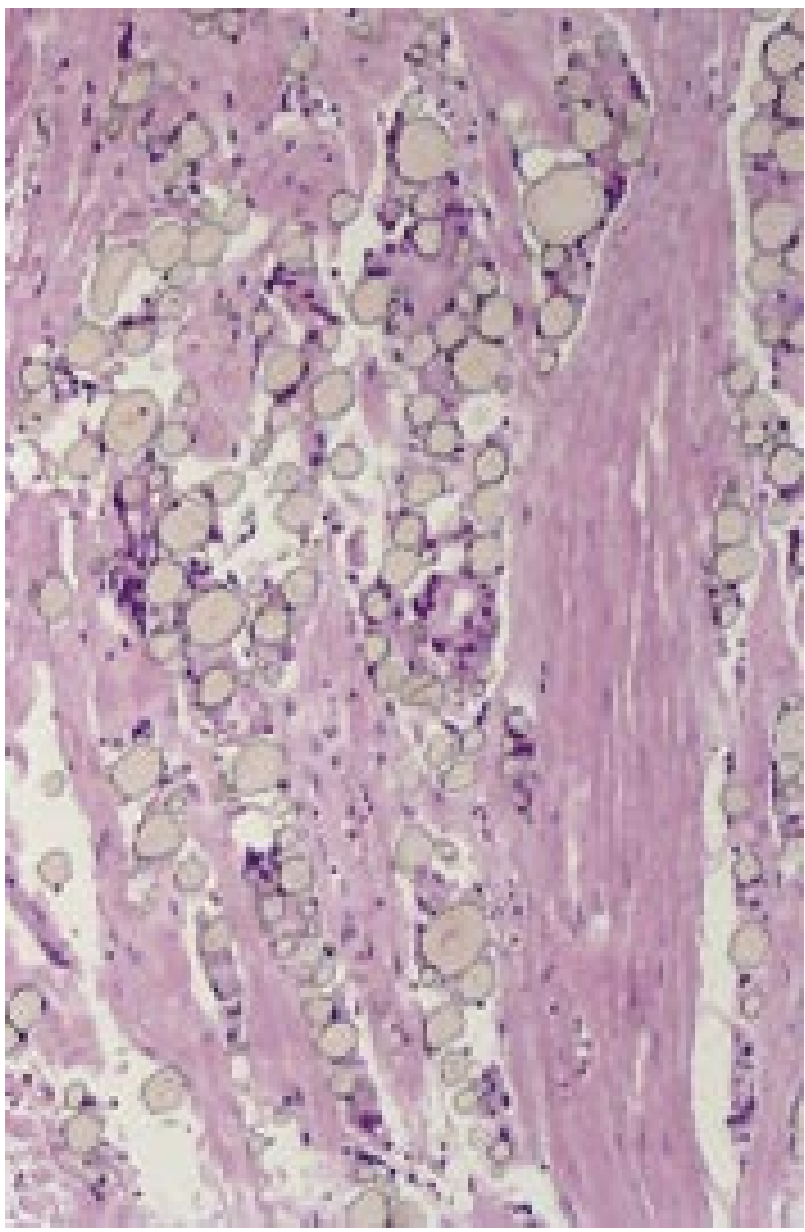

FIGURA 2. Abundantes células gigantes tipo macrófagos conteniendo microesferas de Teflon $®$ en su citoplasma. 


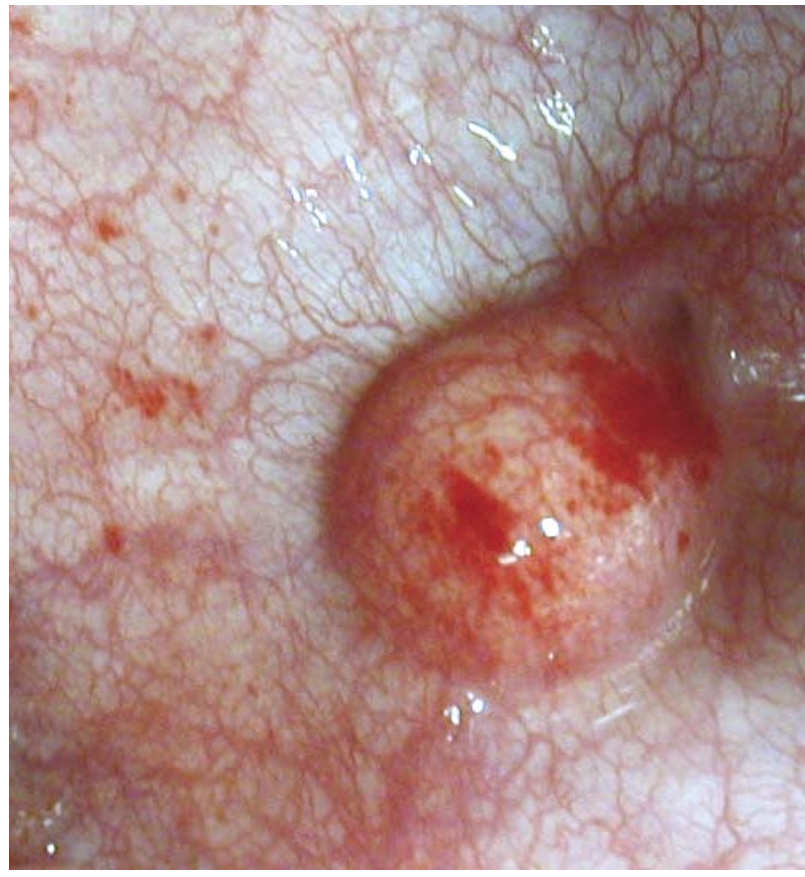

FIGURA 3. Habón izquierdo con mala ubicación: anterior y medial. A diferencia del Teflon $尺$, ofrece un fácil plano de disección por menor reacción a cuerpo extraño.

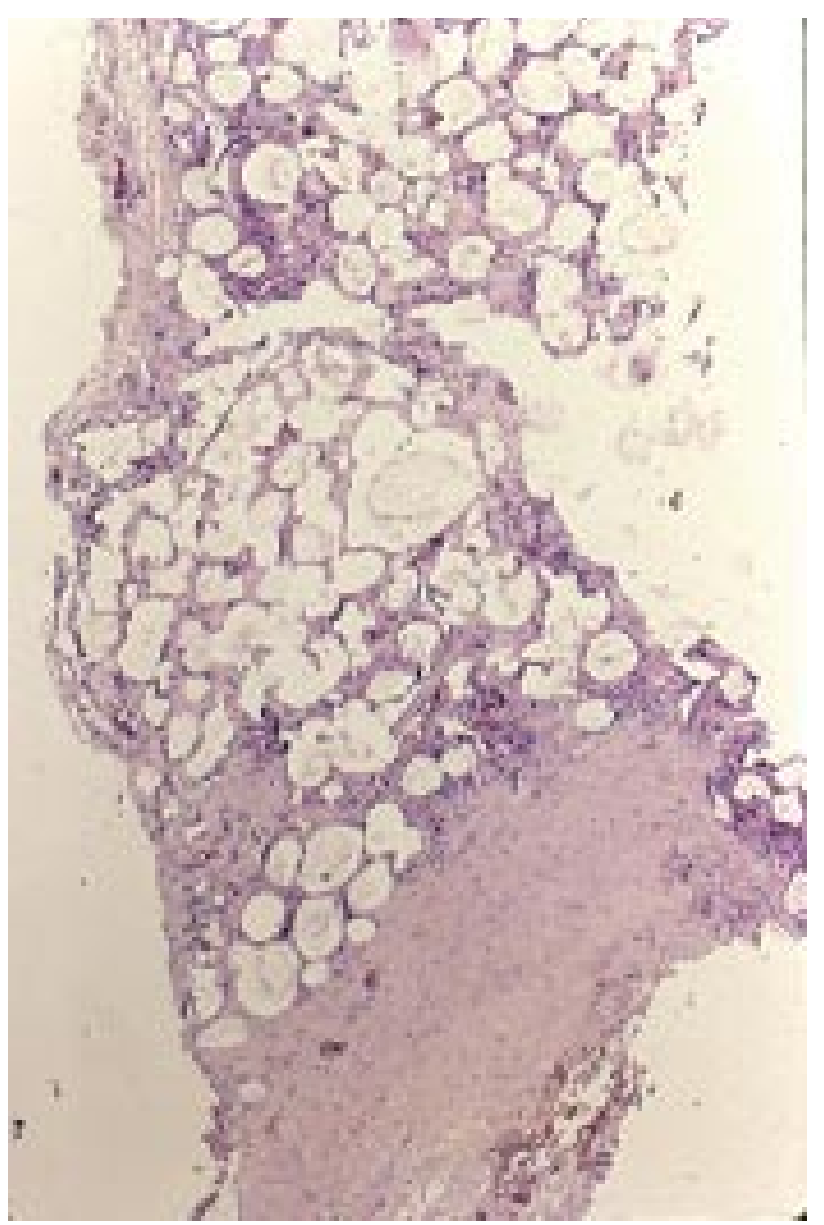

la histología encontrada en 3 niños tratados con diferentes materiales.

\section{MATERIAL Y MÉTODOS}

Presentamos la histología de 3 muestras de uréter intravesical de 3 niños tratados con politetrafluoroetileno (Teflon®), polidimetilsiloxano (Macroplástico®), copolímero de dextranómero y ácido hialurónico (Deflux®) respectivamente. Las piezas de uréter distal se obtuvieron durante la reimplantación ureteral.

El primer caso se trató de una niña con reflujo vesicoureteral derecho de grado III, al que se realizó tratamiento antirreflujo por vía endoscópica con politetrafluoroetileno. La inyección fue con $0^{\prime} 8 \mathrm{cc}$ de este material de la forma descrita por O'Donnell y P. Puri (9). Tras la primera inyección, se hizo control cistográfico en el que se observó una persistencia del reflujo grado III. A razón de estos hallazgos se planteó una segunda inyección con lcc del mismo material. En el segundo control tras esta intervención, se mantiene un reflujo grado III por lo que se decidió la reimplantación por vía abierta según técnica de Cohen. En este acto quirúrgico y tras la exteriorización del uréter, se

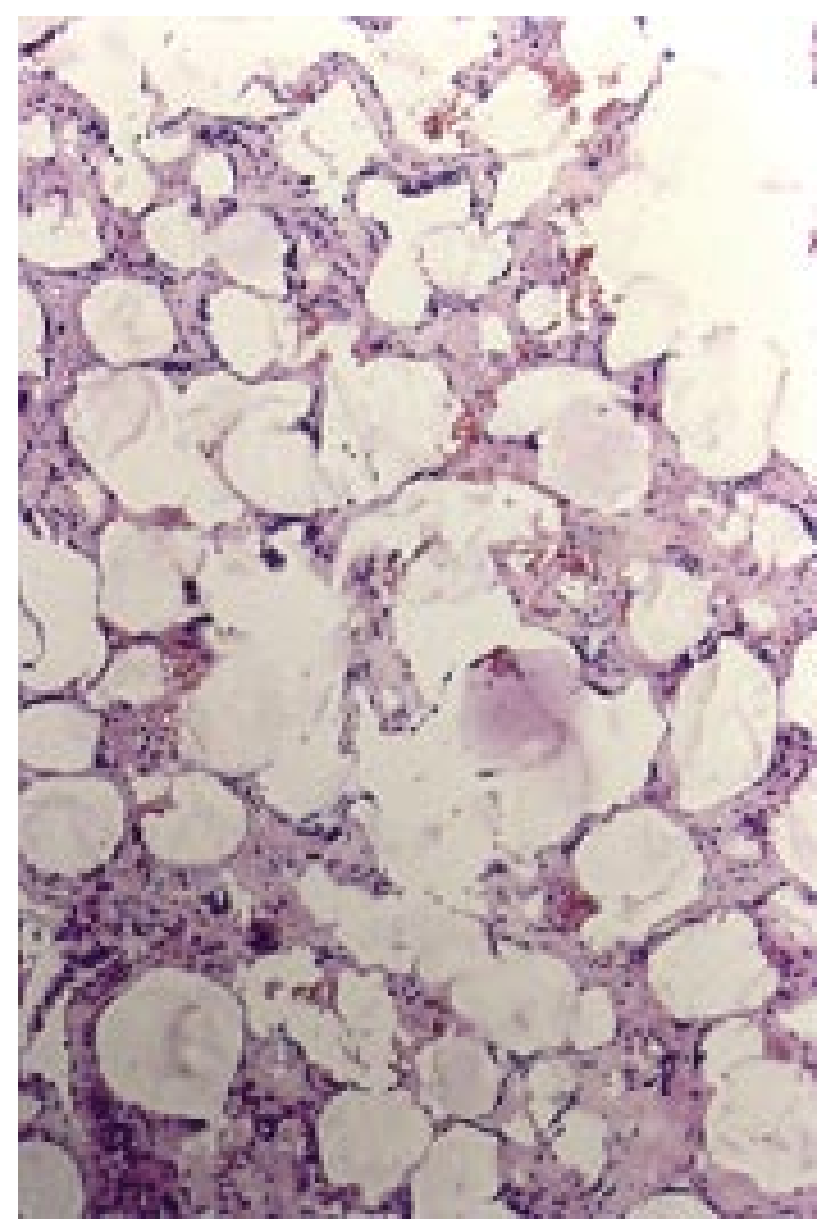

FIGURA 4. En el tejido ureteral con inyección de polidimetilsiloxano se vieron menor número de macrófagos y menor número de bandas de tejido conjuntivo. 


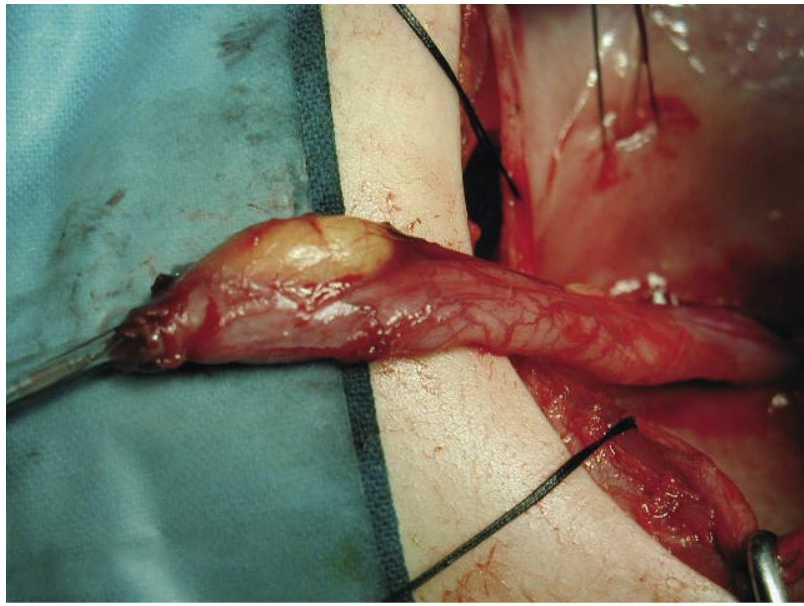

FIGURA 5. Nítida delimitación entre uréter y material inyectado (Deflux $\circledast$ ).

resecó la porción distal del uréter, enviando dicha muestra para análisis anatomopatológico.

El segundo caso fue un niño de 5 años con reflujo grado II izquierdo y grado III derecho al que se inoculó polidimetilsiloxano. En el control cistográfico apareció un reflujo bilateral grado III y se reintentó el tratamiento endoscópico; el cual, es de nuevo ineficaz por lo que se realizó un reimplante ureteral bilateral tipo Cohen.

El tercer y último paciente fue una niña de 5 años con un reflujo derecho al diagnóstico grado IV y que fue tratada con inyección de copolímero de dextranómero y ácido hialurónico. En los controles de ecocistografía se mantuvo un reflujo grado III por lo que se repitió el pro- cedimiento. Ante la persistencia del reflujo a pesar de la segunda inyección y la presencia de infecciones urinarias se realizó reimplante ureteral intravesical (Cohen).

El estudio de las piezas por parte del Servicio de anatomía patológica fue con tricrómico de Masson y microscopía óptica.

\section{RESULTADOS}

En la cirugía abierta de los 3 casos se resecó la porción distal de los uréteres operados para el análisis histopatológico.

En el examen macroscópico y durante la disección del uréter del primer caso (Teflón®) se observó una fuerte adherencia del material inyectado a los tejidos adyacentes con una intensa reacción a cuerpo extraño (Figura 1). La histología mostró imágenes redondeadas claras perfectamente encapsuladas y bandas anchas de tejido conjuntivo (color rojizo), que separaban las partículas de politetrafluoroetileno. Se observaron también abundantes células gigantes tipo macrófagos, conteniendo microesferas de teflón en su citoplasma (Figura 2). En la macroscopía del uréter distal en el niño tratado con Macroplástico $\gtrless^{2}$ ya se observó una diferencia con el anterior, la menor adherencia a tejidos; permitía una más fácil disección del mismo debido a una menor reacción a cuerpo extraño (Figura 3). En cuanto a la microscopía en este caso se vio menor reacción inflamatoria a cuerpo extraño: son imágenes redondeadas claras (polidimetilsiloxano) más próximas entre sí. Algunas están mal delimitadas por no estar bien encapsuladas. En el tejido ureteral con inyección de polidimetilsiloxano se vieron menor número de macrófagos y menor número de bandas de tejido conjuntivo (Figura 4). En el caso del copolímero
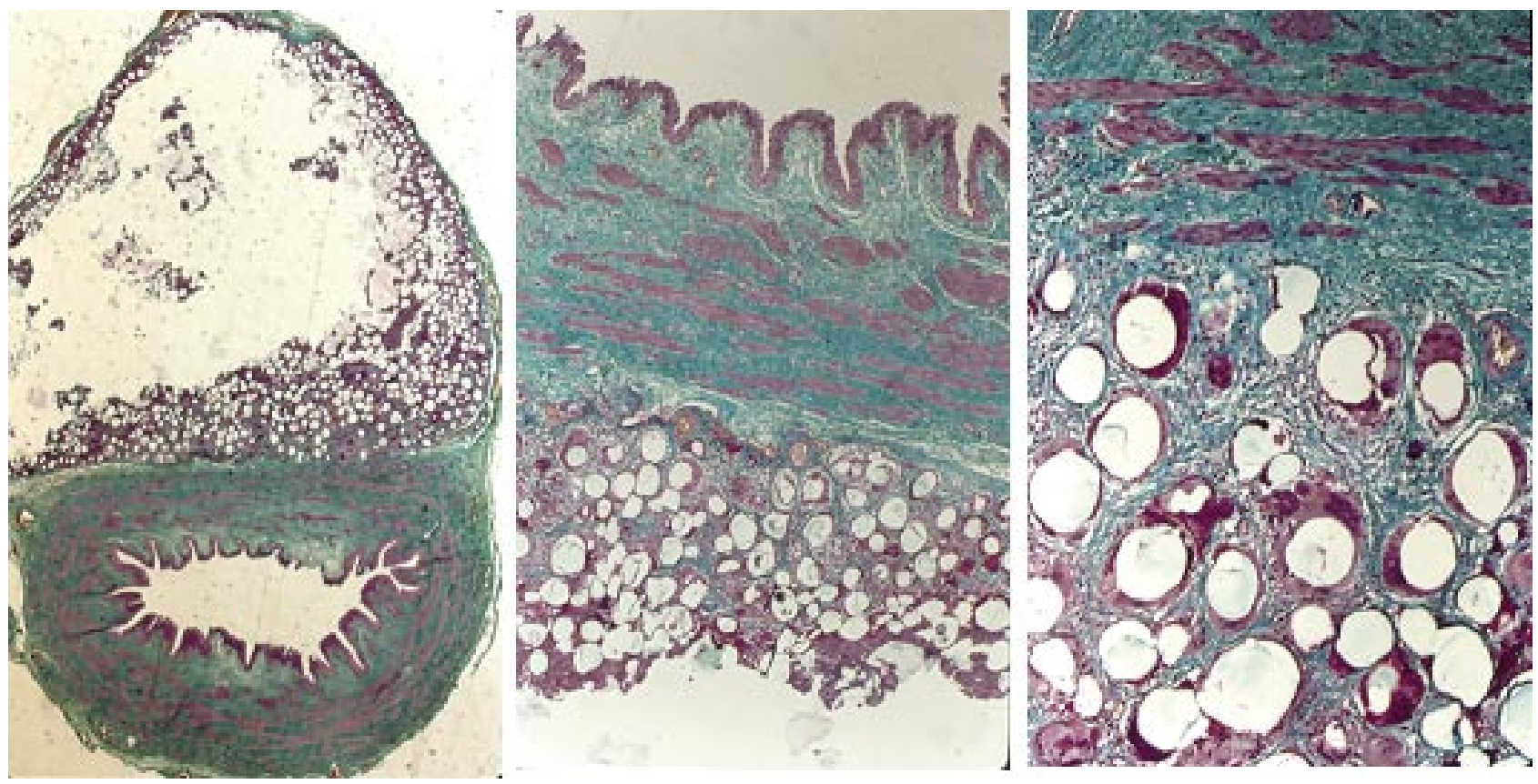

FIGURA 6. Moderada reacción a cuerpo extraño: Microesferas de dextrano próximas entre sí y moderadamente encapsuladas, por la escasa formación de tejido conjuntivo. 
de dextranómero y ácido hialurónico la disección también se hizo de forma sencilla entre el material y los tejidos adyacentes (Figura 5). Microscópicamente se delimitan partículas de dextranómero muy próximas entre sí con reacción a cuerpo extraño yuxtaureteral escasamente encapsuladas por tejido conjuntivo. Un año después del tratamiento endoscópico: persisten microesferas de dextranómero, pero mayoritariamente han sido reabsorbidas y sustituidas por secreción endógena de colágeno (Figura 6).

\section{DISCUSIÓN}

Hay poca literatura sobre los efectos de estos materiales sobre los tejidos en humanos. En el tramo vesical del uréter se producen una serie de cambios en los niños con reflujo vesicoureteral. Estos cambios se modificarán con la inyección de diferentes materiales. En la literatura se recogen estudios que hacen pensar que en el reflujo vesicoureteral intervienen una serie de factores, entre los que se implican estructuras a nivel tisular. En el estudio de Sofikerim sobre 24 uréteres concluye, que el uréter refluyente de estos niños se diferencia del normal en que tienen unas fibras musculares lisas desorganizadas con edema, y una alteración en la estructura de las células musculares lisas. Pero no puede definir si es primario o secundario, lo que sí que se ve es que a mayor grado de reflujo, mayor daño en el músculo liso (lo que explica la baja tasa de resolución espontánea en estos grados) (10). Esto también se recoge en el estudio de Arena sobre la importancia del marcador c-kit en las células intersticiales de Cajal $(\mathrm{ClC})$; en él se observa como existe una disminución de del marcador c-kit para las $\mathrm{CIC}$ y que tiene una correlación inversa con el grado de reflujo (11).

En los estudios de Malizia en 1984 se demostraba como el Teflon $\circledast$ era capaz de formar granulomas en los sitios de inyección y a distancia (12). En nuestro estudio se vieron imágenes redondeadas encapsuladas con bandas anchas de tejido conjuntivo que separaban las partículas de politetrafluoroetileno. Así se contribuye a solidificar el habón y a que permanezca su efecto antirreflujo a pesar de la reabsorción mayor del $50 \%$ del habón (por reabsorción de la glicerina en su totalidad y de las micropartículas de PTFE parcialmente por fagocitosis, sin ser sustituidas por secreción endógena). Aaronson también demostró de forma experimental como estas partículas podían migrar hasta el cerebro (13). Vistos los resultados experimentales, se decidió la introducción de nuevos materiales como el polidimetilsiloxano; pero en nuevos estudios se observó que este material también tenía capacidad de migrar (14). En el caso del dextranómero en nuestro caso se vieron los hallazgos similares a otros estudios. Incluso el estudio experimental y clínico de Stenberg reveló la presencia de células gigantes entre microesferas, crecimiento de fibroblastos y colágeno alrededor de los dextranómeros y reacción inflamatoria tipo reacción a cuerpo extraño sin necrosis tisular ni calcificación $(7,15,16)$. Nosotros hemos visto un más fácil plano de separación con los tejidos por su escasa reacción a cuerpo extraño.

Se mantienen y es importante seguir con los estudios histológicos a este nivel para la mejor elección del material endoscópico a usar en el reflujo vesicoureteral de los niños.

\section{BIBLIOGRAFÍA Y LECTURAS RECOMENDADAS (*lectura de interés $y^{* *}$ lectura fundamental)}

1. REPORT OF A MEETING OF PHYSICIANS AT THE HOSPITAL FOR SICK CHILDREN GOS LONDON.:

"Vesicoureteric reflux: All in the genes?". Lancet, 348: $725,1996$.

2. WHEELER, D.; VIMALACHANDRA, D.; HODSON, E.M. y cols.: "Antibiotics and surgery for vesicoureteric reflux: A meta-analysis of randomised controlled trials". Arch. Dis. Child., 88: 688, 2003.

3. KIRSCH, A.; HENSLE, T.; SCHERZ, H. y cols.: "Injection therapy: Advancing the treatment of vesicoureteral reflux". Journal of Pediatric Urology, 2006.

4. GARÍN, E.H.; OLAVARRÍA, F.; GARCÍA-NIETO, V. y cols.: "Clinical Significance of Primaary Vesicoureteral Reflux and Urinary Antibiotic Prophylaxis after Acute Pyelonephritis: A Multicenter, Randomized, Controlled Study". Pediatrics, 117: 626, 2006.

5. JACOBSON, S.H.; HANSSON, S.; JAKOBSSON, B.: "Vesico-ureteric reflux: Occurrence and long-term risks". Acta Paediatr., 431: 22, 1999.

**6. STENBERG, A.; LARSSON, E.; LACKGREN, G.: "Endoscopic treatment with dextranomer-hyaluronic acid for vesicoureteral reflux: Histological findings". J. Urol., 169: 1109, 2003.

7. ALKAN, M.; CIFTCI, A.O.; TALIM, B. y cols.: "Histological response to injected dextranomer-based implant in a rat model". Pediatr. Surg. Int., 23: 183, 2007.

8. RAMSEYER, P.; MEAGHER-VILLEMURE, K.; BURKI, M. y cols.: "(Poly) acrylonitrile-based hydrogel as a therapeutic bulking agent in urology". Biomaterials, 28: 1185, 2007.

**9. O’DONNELL, B.; PURI, P.: "Endoscopic correction of primary vesicoureteral reflux". Br. J. Urol., 58: 601, 1986.

10. SOFIKERIM, M.; SARGON, M.; ORUC, O. y cols.: "An electron microscopic examination of the intravesical ureter in children with primary vesico-ureteric reflux”. BJU Int., 99: 1127, 2007.

11. ARENA, S.; FAZZARI, C.; ARENA, F. y cols.: "Altered "active" antireflux mechanism in primary vesicoureteric reflux: A morphological and manometric study". BJU Int., 26, 2007.

12. MALIZIA, A.A. Jr.; REIMAN, H.M.; MYERS, R.P. y cols.: "Migration and granulomatous reaction after periurethral injection of plytef (Teflon)". JAMA, 251: 3277, 1984.

*13. AARONSON, I.A.; RAMES, R.A.; GREENE, W.B. y cols.: "Endoscopic treatment of reflux: Migration of Teflon to the lungs and brain". Eur. Urol., 23: 394, 1993.

*14. TRAVIS, W.D.; BALOGH, K.; ABRAHAM, J.L.: "Silicone granulomas: Report of three cases and review of the literature". Hum. Pathol., 16: 19, 1985.

15. STENBERG, A.M.; SUNDIN, A.; LARSSON, B.N. y cols.: "Lack of distant migration after injection of a 125Iodine labelled dextranomer based implant into the rabbit bladder". J. Urol., 158: 1937, 1997.

*16. STENBERG, A.; LARSSON, E.; LINDHOLM, A. y cols.: "Injectable Dextranomer-based implant: Histopathology, volume changes and DNA-analysis". Scand. J. Urol. Nephrol., 33: 255, 1999. 